\title{
Grundrechtsschutz durch Legislativverfahren
}

Grundrechtlich induzierte Prozeduralisierung der Gesetzgebung und ihrer Kontrolle im Verfassungs- und Unionsrecht

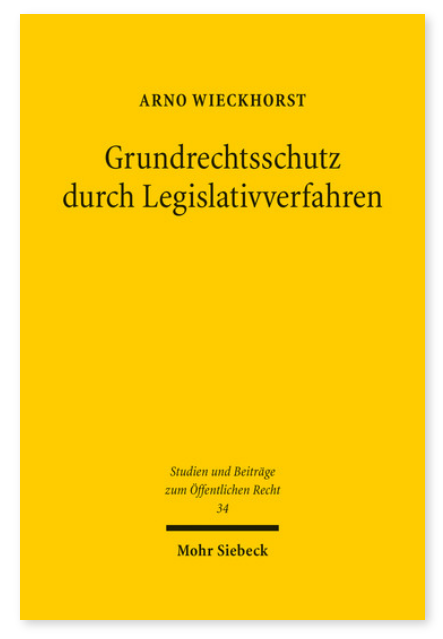

2017. XVIII, 668 Seiten. StudÖR 34

ISBN 978-3-16-155225-0

DOI 10.1628/978-3-16-155225-0

eBook PDF $144,00 €$

ISBN 978-3-16-155208-3

Leinen $144,00 €$
Forderungen nach 'guter' Normsetzung sind für das Grundgesetz nicht neu. An den gesetzgeberischen Entscheidungsprozess gerichtete Rationalitätspostulate bleiben aber kontrovers und spalten auch das BVerfG. Arno Wieckhorst entwickelt eine grundrechtszentrierte Rekonstruktion legislativer Sorgfaltspflichten. Neben der Ermittlung, Bewertung und Abwägung von Tatsachen- und Interessenlagen werden auch legislative Begründungs-, Beobachtungs- und Nachbesserungspflichten einbezogen. Der Eigenwert bundesverfassungsgerichtlicher Verfahrenskontrolle bei gesetzgeberischen Gestaltungsspielräumen wird gegenüber der Abwertung von Verfahrensfehlern verteidigt. So entsteht eine geschlossene Dogmatik des Grundrechtsschutzes durch Legislativverfahren als Ausprägung einer Prozeduralisierung der Grundrechte. Deren status negativus wie positivus processualis kann schließlich auf die Grundrechtecharta übertragen werden und so als Bezugspunkt auch einer unionsrechtlichen Gesetzgebungslehre dienen.

Arno Wieckhorst Geboren 1990; Studium der Rechtswissenschaften an der Friedrich-Schiller-Universität Jena mit Schwerpunkt Deutsches und Europäisches Öffentliches Recht; Wissenschaftlicher Mitarbeiter an der Friedrich-SchillerUniversität Jena; 2016 Promotion; 2016 Wissenschaftlicher Mitarbeiter in einer Wirtschaftskanzlei in Berlin; 2016-17 LL.M.Studium an der Universität Edinburgh.
Jetzt bestellen:

https://mohrsiebeck.com/buch/grundrechtsschutz-durch-legislativverfahren-9783161552250?no_cache=1

order@mohrsiebeck.com

Telefon: +49 (0)7071-923-17

Telefax: +49 (0)7071-51104 